\title{
Implementation Effects of a Pre-service Training Course for Secondary Education Teachers
}

\section{SIMON VEENMAN, JESKA BAKERMANS, YVONNE FRANZEN \& MASJA VAN HOOF}

Department of Educational Sciences, University of Nijmegen, PO Box 9104, 6500 HE Nijmegen, The Netherlands

SUMMARY A quasi-experimental, treatment-control group investigation was designed to test the effects of a pre-service training course for secondary education teachers. Previous findings from teacher effects research and cognitive strategy instruction were translated into two direct instructional models: a model of executive acting directed at well-structured skills and a model of strategic acting directed at higher-level thinking strategies. Pre- and post-training comparison of classroom observations by trained observers revealed significantly more effective instruction by the student teachers after training. No treatment effect was found for pupil engagement rates. The ratings from the supervising teachers did not show significantly better use of the recommended instructional skills by the trained student teachers than by the untrained student teachers.

\section{Introduction}

One of the main tasks of teachers is to utilise instructional strategies that facilitate pupil learning. In order for learning to occur, various learning functions must be performed by the pupil. Learning functions are defined by Shuell (1988) as psychological functions to be performed by the pupil during learning: establishing appropriate expectations, paying attention to the relevant information, encoding the material in an appropriate manner, repetition and practice, obtaining feedback, evaluating the adequacy of performance, monitoring the learning process, and combining and integrating complex material in a meaningful way. These learning functions can be initiated by the teacher and/or by the pupil. When these functions are fulfilled primarily by the teacher, the learning process is controlled by the teacher (teacher-directed learning). The performance of these functions can also be shared by teacher and pupil together (shared responsibility). When the learning functions are fulfilled primarily by the pupil, the learning process is controlled by the pupil (pupil-directed or autonomous learning). Today, cognitive conceptions of both learning and instruction emphasise the active, constructive, cumulative, and goal-oriented nature of 
learning (Shuell, 1988). These current conceptions of learning and instruction stress the responsibility of the pupils for their own learning. Although the learning functions can be initiated by either the teacher or the pupil, it is the pupil who must actually carry out the functions.

This view of learning is also embedded in a recent publication by the Dutch governmental committee responsible for the formulation of the guidelines for the restructuring of secondary education (Stuurgroep Profiel Tweede Fase Voortgezet Onderwijs, 1994). The pedagogical, didactic, and organisational changes that this committee proposes are summarised by the concept of 'the school as a study house'. This includes notions of self-regulated learning, the interactive nature of teaching and learning, and the active participation of pupils in the achievement of learning outcomes. In this conception of the school as a study house, the teacher acts more like a coach than a transmitter of knowledge. Greater pupil responsibility for his or her own learning does not imply that the learning functions may not be initiated by the teacher. The active, constructive process of acquiring new knowledge and skills has to be guided by appropriate forms of instruction including direct explanation, modelling, teacher-guided pupil practice, focused assistance when pupils experience failures or difficulties, and the provision of support. When a pupil has insufficient prior knowledge of a subject or confronts complex material, the teacher may need to perform the various learning functions at first and gradually shift the control of these learning functions into the hands of the pupil. As pupils acquire more and more domain-specific knowledge and learn to apply different learning strategies and metacognitive skills in a variety of contexts, they will also be better equipped to bear the responsibility for their own learning.

An empirically validated instructional approach for the regulation of the learning functions in the first phases of the learning process is the direct instructional model. This model was selected for a secondary education teacher training programme. The model has proved useful in a primary education teacher training programme, and the present study is based partly on the positive findings for this programme published previously in Educational Studies (see Veenman et al., 1993). The teacher training courses for secondary education lacked such a programme, however, so the Protestant Educational Advisory Centre (CPS) and the Department of Educational Sciences of the University of Nijmegen undertook the design of such a programme.

\section{Direct Instruction}

As used in this study, the concept of direct instruction is a label for the constellation of effective teacher behaviours isolated by Rosenshine \& Stevens (1986) and Brophy \& Good (1986) from correlational and experimental studies. The core of the underlying instructional model consists of six functions: (1) daily review, (2) presenting new material, (3) guided practice, (4) independent practice, (5) providing feedback and correctives, and (6) weekly and monthly review. In the present study, moreover, these steps are incorporated into the 
direct instructional model of executive acting and the direct instructional model of strategic acting.

In education, a great deal of time is devoted to the direct teaching of executive acts. Acts are purposive physical or mental/cognitive operations, and executive acting is directed at the achievement of a particular result or product (Van Parreren, 1988). This manner of acting is characteristic of academic tasks that must be performed according to a fixed scheme or framework. The direct instructional model of executive acting is best suited, thus, to skill and knowledge domains that are hierarchically organised and require pupils to learn in a linear sequence. These domains may include mathematical procedures and computations, reading decoding skills, map skills, grammatical concepts and rules, foreign language vocabulary and grammar, science facts and rules.

The six steps in the instructional model of executive acting include the review of the prerequisite skills, the review of relevant past learning, reteaching when necessary (=daily review), a short statement of the lesson objective and structure, proceeding in small steps but nevertheless at a rapid pace, asking questions to check pupil understanding, highlighting the main points, the provision of concrete examples, demonstration (=presentation), initial pupil practice with teacher guidance, the provision of additional explanation and prompts when necessary, assessment of independent practice (= guided practice), the provision of uninterrupted successful practice directly relevant to the skills and content taught, notifying pupils that their work will be checked ( = independent practice), reviewing previously taught material, frequent testing, reteaching of material missed in tests (= weekly and monthly review), monitoring pupils for systematic errors, the provision of process feedback, and the correction of systematic errors (= feedback and correctives). Research has shown the direct instructional model of executive acting to be a successful approach to the teaching of the basic subjects in primary and secondary schools (Brophy \& Good, 1986; Rosenshine \& Stevens, 1986).

In contrast to executive acting directed at the attainment of a specific goal, strategic acting is aimed at the planning and monitoring of subsequent new acts. One acts strategically to improve the processes necessary for successful performance (Van Parreren, 1988). In instructional settings, strategic acting applies tò areas that cannot be broken into smaller parts and are less well-structured skills that do not follow explicit steps, and academic tasks that cannot be performed by following a fixed schema of subskills. For example, essay composition, the writing of term papers, reading comprehension, the analysis of literary or historical trends, and advanced mathematical problem-solving do not depend on a fixed sequence of behaviours. Strategic teaching is therefore directed at the development of higher-level cognitive strategies.

In the direct instructional model of strategic acting, attention is paid to the expansion of the pupils' knowledge base and also to the expansion of the repertoire of learning strategies. The explicit teaching of strategies and establishment of a metacognitive understanding are important features of the direct instructional model of strategic acting. Specific strategies may be extensively 
modelled by the teacher along with explanations of the use of the complete strategy sequence, and information with regard to the utility of the strategy being taught. The instructional model of strategic acting is based on cognitive strategy instruction (Borkowski \& Muthukrishna, 1992; Pressley et al., 1989), or what is sometimes called cognitive apprenticeship (Collins et al., 1989).

A major organising concept in the teaching of higher-level thinking strategies is that of scaffolding. Scaffolding refers to the instructional support that pupils receive in order to bridge the gap between their current abilities and the goal. The scaffold or support is temporary and highly adjustable; it is used to assist the learners and is gradually withdrawn as the learners become more independent (Palincsar \& Brown, 1989; Rosenshine \& Meister, 1992). Scaffolds may include: modelling of the skills or strategies by the teacher, thinking aloud in order to make the mental processes of an expert 'visible' (cf. Schoenfeld, 1985), the provision of procedural facilitators (cf. Bereiter \& Scardamalia, 1987), reciprocal teaching (cf. Palincsar \& Brown, 1984), prompts, aids, guidance from the teacher, the provision of models of finished work in order to allow the pupils to compare their work to that of an expert, and the provision of check-lists in order to assist pupils in the development of a critical eye towards their work. Although the concept of scaffolding can also apply to the direct instructional model of executive acting, it is most relevant to the teaching of higher-level cognitive skills (Rosenshine \& Meister, 1992).

The core of the instructional model of strategic acting is largely identical to that of the model of executive acting: review, presentation of new material in small steps, guiding initial pupil practice, the provision of extensive independent practice, and the provision of feedback and correctives. Based on the work of Borkowski \& Muthukrishna (1992), Pressley et al. (1990), and Rosenshine \& Meister (1992), the instructional model of executive acting has been supplemented with elements from the cognitive strategy instruction literature and the literature on cognitive apprenticeship. For example, the teaching function 'independent practice' has been extended with such teaching behaviours as: engage in reciprocal teaching, have pupils work in small groups or pairs, facilitate application to new examples, and have pupils plan; monitor and evaluate their own work (self-regulation). In our study, both the model of executive acting and the model of strategic acting are used to teach effective instruction to pre-service teachers in secondary schools.

\section{Research Questions}

In the present study, the effects of training based on a direct instructional model of executive acting and a direct instructional model of strategic acting are examined. The research questions that guided the study were the following: (1) Do student teachers who participated in the course on effective instruction implement the desired teaching behaviours as presented in the two instructional models? (2) Does the course on effective instruction appear to have an effect on the pupil engagement rates in the classes with student teachers who participated 
in the course? (3) Do the student teachers and teacher educators appear to value the new course?

\section{Method and Instrumentation}

Design

The study contained three substudies: (1) an observational study using trained observers; (2) an observational study using the supervising teachers; and (3) a questionnaire and interview study focusing on the reactions of the participants to the course. Both of the observational studies were focused on the degree of implementation of the desired teaching behaviours.

The first observational sub-study with ratings by trained observers was set up as a quasi-experimental pre-test-post-test field study with treatment $(n=27)$ and control $(n=24)$ groups of student teachers (and the pupils associated with each student teacher). The second observational substudy with ratings by the supervising teachers was also set up as a pre-test-post-test study with treatment (pre-test $n=18$; post-test $n=19$ ) and control (pre-test $n=15$; post-test $n=20$ ) groups of supervising teachers. In order to gain information on the perceptions of the student teachers $(n=64)$ and the teacher educators $(n=3)$, questionnaires and interviews were used in a third substudy.

\section{Subjects}

The participants in the study were secondary school student teachers from three teacher training colleges enrolled in either their second or third year. College $\mathrm{A}$ was located in the south of the country; college B in the east; and college C in the south-east of the country. In each college, one class was selected for training. All of the student teachers in these three classes $(n=64)$ were instructed in the direct instructional models and thus constituted the treatment group. In each college, student teachers from parallel classes $(n=71)$ followed their traditional educational programmes and thus constituted the control group. In all of the three teacher training colleges, the course on effective instruction was conducted by a single teacher educator. For logistic reasons (budget, time constraints, and available observers), a small set of the student teachers in the treatment classes was randomly selected for observational study. From the three treatment classes, 27 student teachers were thus observed (14 from college A, six from college $B$, and seven from college $C$ ). From the control classes, 24 student teachers were observed ( 10 from college $A$, four from college $B$, and 10 from college C).

Prior to and after the course on effective instruction, the supervising teachers were asked to rate the performances of their student teachers. Of the 51 distributed rating scales, 33 were actually returned by the supervising teachers during the pre-test (treatment group $n=18$, control group $n=15$ ). With regard to the post-test, 39 of the distributed rating scales were returned by 
the supervising teachers (treatment group $n=19$, control group $n=20$ ) (total response rate of $71 \%$ ).

Questionnaires were used to obtain information on the student teachers' perceptions of the content of the course (primarily the textbook) and their experiences with the implementation of the two models of direct instruction. The questionnaires were distributed to all of the 64 student teachers who participated in the effective instruction course. Of these student teachers, 44 returned the questionnaire (response rate of $69 \%$ ). Interviews were conducted with the three teacher educators in order to obtain further information on the implementation of the course and any suggestions for improvement.

\section{Direct Instruction Scale}

After each observation, the Direct Instruction Scale (DIS) was used by the observers and supervising teachers to assess the student teacher's behaviour with regard to a number of instructional skills. The five-point scales addressed the skills in the instructional model of executive acting and the instructional model of strategic acting. The variables from the DIS, listed in Tables I and II, are based on the research of Rosenshine \& Stevens (1986), Rosenshine \& Meister (1992), Pressley et al. (1989), and an earlier version of the DIS used to evaluate a course on effective instruction for primary school teachers Veenman et al., 1993). Not all of the instructional skills found in the two models were included in the DIS. Only the most representative instructional skills were selected. Because of the restricted number of observations, moreover, a single scale was constructed for use with both of the instructional models. This decision was based on the assumption that although instructional skills such as modelling, reciprocal teaching, and the use of scaffolds are particularly useful for the direct instructional model of strategic acting (that is, for teaching higher-level cognitive skills), such skills can also be applied in the direct instructional model of executive acting (that is, for teaching well-structured skills). This suggests that a continuum from the teaching of well-structured skills to the teaching of cognitive strategies (Rosenshine \& Meister, 1992) may exist rather than a dichotomy.

Prior to the collection of the observational data, the three observers went through a training programme consisting of about 40 hours. The programme involved the coding of lesson videotapes as well as the live coding of 17 lessons. Inter-observer reliability checks based on the live coding of 12 lessons (including mathematics, history and foreign language instruction) conducted at a school not involved in the study and estimated through analysis of variance for the separate instructional variables ranged from 0.60 to 0.99 (median 0.82 ). Two items with estimates lower than 0.60 were removed from the scale.

On conceptual grounds, the 24 items constituting the rating scale were divided into three subscales: (1) presentation skills (the teacher initiates the learning functions, including daily review); (2) guided practice skills (shared responsibility for the learning functions by the teacher and pupils); and 
(3) independent practice skills (the pupil initiates the learning functions while the teacher monitors pupil work and follows the structure of the directinstructional model). Measures of internal consistency (Cronbach's alpha) were computed for the entire scale and for each subscale for the data obtained from the trained observers and the data obtained from the supervising teachers. The alpha-coefficients for the scale and subscales used by the trained observers ranged from 0.63 to 0.86 ; for the scale and subscales used by the supervising teachers from 0.58 to 0.87 (see Tables I and II). Scores were then computed for the entire scale, each subscale and each item.

The observers had no knowledge of the group to which the student teachers had been assigned. After each pre-test and post-test lesson, the supervising teachers were also asked to complete the DIS.

\section{Pupil Engagement Rates}

Every 10 minutes during the lesson taught by the student teacher, the observer stopped note-taking and recorded the number of pupils in the class who were engaged in academic activities (on-task). An on-task score for the class was obtained by dividing the number of pupils engaged in the task by the total number of pupils present, yielding a percentage of pupils classified as on-task. Each observation period lasted approximately 50 minutes and resulted in four on-task estimates. The inter-observer reliability for the on-task checks was estimated using analysis of variance (Winer, 1971) and revealed a coefficient of 0.85 .

\section{Lesson Format}

In order to control for the possible influence of lesson content, some guidelines were provided. These guidelines invited the student teachers to use the instructional skills from the two models of direct instruction. The student teachers were asked to teach a lesson that matched with the ongoing curriculum of the co-operating school. These student teachers were also asked to present new learning material and to create opportunities for independent practice or small group work. Finally, all of the student teachers were asked not to give their pupils a dictation or a test.

\section{The Instructional Course}

In the course 'Effective instruction in secondary schools: learning to teach with the direct instructional model' (Veenman et al., 1994), two versions of the direct instructional model were presented: one model of executive acting and one model of strategic acting. The student teachers were also instructed to apply the models presented in the course in the co-operating school. The course consisted of six sections. In section one, topics such as the nature of learning, metacognition, self-regulation, and effective strategy instruction were discussed. In section 
two, the characteristics of a good strategy user and examples of strategy instruction for different subject areas were provided. In section three, the preparation of a lesson incorporating the steps of the direct instructional model was discussed. In sections four and five, the model of executive acting and the model of strategic acting were presented. Their use was then illustrated for the teaching of such subjects as language, foreign languages, mathematics, biology, economics, physics and geography. That is, concrete illustrations of just how the instructional models might be used were clearly presented in these sections of the course. In section six, some of the prerequisites for effective instruction were discussed: effective classroom management and the prevention of disorderly classroom situations.

The course on effective instruction at the three different colleges was taught by three experienced teacher educators. Two of the three teacher educators had been previously involved in the design and implementation of an in-service programme on effective instruction, which involved the direct instructional model. The third teacher educator had experience teaching courses on metacognitive learning skills. The student teachers of this teacher educator were in their third year of training while the student teachers of the other two teacher educators were in their second year of training. Because all of the student teachers were familiar with the concepts of learning to learn, the instructional skills presented in the course on effective instruction were not completely unfamiliar to them. In the present course, these instructional skills were systematically placed in the context of the direct instructional model. The content of the course constituted the basis for a one-day workshop for the three teacher educators. Prior to this workshop-provided by the four authors of the present study - the course was sent to the teacher educators with the request to study it carefully. During the workshop, attention was then paid to the content of the course, the educator's role during the student teachers' training period, and the design of the evaluation study.

The average number of hours devoted to the course was 8.5. At location A, three classes-each lasting 2 hours-were devoted to the course and during an additional three classes the student teachers conducted mini-lessons in order to practise the two instructional models. During these mini-lessons, performance feedback was provided by the teacher educator. The lessons taught by the student teachers at the co-operating school were also discussed by the student teachers and the teacher educator. At location B, six classes-each lasting 100 minutes-were devoted to the course on effective instruction. During half of the classes, the student teachers conducted mini-lessons, which were then discussed by the student teachers and the teacher educator. At location C, five classeseach lasting 100 minutes-were devoted to the course. In duos and trios, the student teachers designed lesson plans using the two instructional models and discussed them with their teacher educator. At locations $A$ and $C$, two additional classes had been cancelled due to external circumstances. Most of the training time was devoted to the use of the two instructional models (Chapters 4 and 5 of the course). Although the three educators were asked to structure 
TABLE I. Mean ratings by trained observers on variables from the Direct Instructional Scale (DIS), results of $t$-test on differences between pre- and post-test data for treatment and control student teachers, and ANCOVA test results

\begin{tabular}{|c|c|c|c|c|c|c|c|c|c|c|c|}
\hline \multirow[t]{3}{*}{ DIS/subscales/items } & & \multicolumn{4}{|c|}{ Treatment group } & \multicolumn{5}{|c|}{ Control group } & \multirow[t]{3}{*}{$\mathbf{F}$} \\
\hline & & Pre-test & \multicolumn{3}{|c|}{ Post-test } & \multicolumn{2}{|c|}{ Pre-test } & \multicolumn{3}{|c|}{ Post-test } & \\
\hline & $\mathbf{M}$ & SD & $\mathbf{M}$ & SD & Adj.M & $\mathbf{M}$ & SD & $\mathbf{M}$ & SD & Adj.M & \\
\hline DIS total (24 items, $\alpha=0.86$ ) & 56.8 & 9.4 & $70.4^{\star \star}$ & 8.8 & 69.8 & 54.8 & 11.1 & 58.5 & 9.2 & 59.1 & $17.6^{\star \star}$ \\
\hline \multicolumn{12}{|l|}{ Subscale presentation } \\
\hline (9 items, $\alpha=0.75$ ) & 20.5 & 4.0 & $26.3^{\star \star}$ & 4.9 & 26.0 & 19.2 & 5.5 & 21.3 & 3.9 & 21.5 & $13.5^{\star \star}$ \\
\hline Daily review & 2.6 & 1.6 & $4.6^{\star \star}$ & 0.8 & 4.7 & 1.5 & 1.0 & $3.3^{\star \star}$ & 1.5 & 3.3 & $11.4^{\star \star}$ \\
\hline Activating prior knowledge & 2.3 & 1.5 & 2.4 & 1.4 & 2.4 & 2.5 & 1.6 & 2.0 & 1.6 & 2.0 & $<1.0$ \\
\hline State lesson goals & 1.9 & 0.6 & 2.0 & 1.0 & 2.0 & 1.7 & 0.6 & 1.6 & 0.7 & 1.6 & 1.6 \\
\hline Provide procedural facilitators & 2.9 & 0.9 & $3.6^{\star \star}$ & 0.9 & 3.6 & 2.8 & 1.3 & 3.1 & 0.8 & 3.1 & 3.8 \\
\hline Model the use of strategies & 1.1 & 0.6 & $1.7^{\star}$ & 1.0 & 1.6 & 1.2 & 0.4 & 1.5 & 1.0 & 1.5 & $<1.0$ \\
\hline Underline the importance of & & & & & & & & & & & \\
\hline strategies & 1.4 & 0.9 & $2.2^{\star \star}$ & 1.4 & 2.2 & 1.5 & 0.9 & 1.5 & 0.5 & 1.5 & $5.7^{\star}$ \\
\hline Provide concrete examples & 3.9 & 0.8 & 4.0 & 0.7 & 4.0 & 3.5 & 1.1 & $3.9^{\star}$ & 0.9 & 4.0 & $<1.0$ \\
\hline Provide summaries & 1.2 & 0.6 & $1.9^{\star}$ & 1.4 & 1.9 & 1.7 & 1.2 & $1.2^{\star}$ & 0.5 & 1.2 & $4.4^{\star}$ \\
\hline Activate thinking processes & 3.3 & 1.1 & $4.0^{\star}$ & 1.1 & 3.9 & 2.9 & 1.2 & 3.0 & 1.2 & 3.1 & $5.3^{\star}$ \\
\hline \multicolumn{12}{|c|}{ Subscale guided practice } \\
\hline$(5$ items, $\alpha=0.76)$ & 15.6 & 3.8 & $19.2^{\star \star}$ & 3.4 & 18.9 & 15.2 & 3.7 & 16.2 & 4.5 & 16.5 & $4.5^{\star}$ \\
\hline \multirow{2}{*}{\multicolumn{12}{|c|}{ Have pupils make their strategies }} \\
\hline & & & & & & & & & & & \\
\hline explicit & 2.5 & 1.4 & $3.2^{\star}$ & 1.6 & 3.1 & 2.3 & 1.4 & 2.4 & 1.6 & 2.5 & 1.8 \\
\hline Checking for understanding & 2.3 & 1.3 & 2.3 & 1.0 & 2.3 & 1.9 & 0.9 & 2.0 & 1.1 & 2.1 & $<1.0$ \\
\hline Provide process feedback & 3.3 & 1.0 & $4.3^{\star \star}$ & 0.7 & 4.3 & 3.2 & 1.0 & $3.7^{\star}$ & 1.2 & 3.8 & 3.4 \\
\hline Provide correctives & 3.5 & 1.0 & $4.5^{\star \star}$ & 0.6 & 4.5 & 3.6 & 1.1 & 3.8 & 1.2 & 3.8 & $5.8^{\star}$ \\
\hline \multicolumn{12}{|l|}{ Subscale independent practice } \\
\hline (10 items, $\alpha=0.63$ ) & 20.7 & 3.2 & $24.9 \star \star$ & 3.9 & 24.7 & 20.4 & 3.6 & 21.0 & 3.0 & 21.1 & $11.6 \star \star$ \\
\hline Engage in reciprocal teaching & 1.2 & 0.6 & 1.3 & 0.7 & 1.2 & 1.3 & 0.6 & 1.4 & 0.7 & 1.4 & $<1.0$ \\
\hline Stimulate pupil engagement & 3.7 & 0.6 & $4.3^{\star \star}$ & 0.9 & 4.3 & 3.3 & 0.6 & $3.9 \star \star$ & 0.7 & 3.9 & 2.0 \\
\hline \multicolumn{12}{|l|}{ Effective monitoring (pupils begin } \\
\hline work quickly) & 3.6 & 0.9 & 3.8 & 1.3 & 3.8 & 3.5 & 0.8 & 3.8 & 1.0 & 3.7 & $<1.0$ \\
\hline Have pupils help each other & 2.1 & 0.8 & 1.9 & 0.6 & 1.9 & 2.1 & 1.1 & $1.6^{\star}$ & 0.6 & 1.6 & 3.3 \\
\hline Provide cues for transfer & 1.4 & 0.9 & 1.7 & 1.3 & 1.7 & 1.4 & 0.8 & 1.5 & 1.2 & 1.5 & $<1.0$ \\
\hline Active processing of information & 3.2 & 0.7 & $4.1 \star \star$ & 0.9 & 4.1 & 3.0 & 1.0 & 3.1 & 0.9 & 3.1 & $13.7^{\star \star}$ \\
\hline \multicolumn{12}{|l|}{ Have pupils plan their work } \\
\hline (self-regulation) & 1.0 & 0.2 & $1.7^{\star \star}$ & 1.2 & 1.7 & 1.3 & 0.7 & 1.1 & 0.3 & 1.1 & $4.8^{\star}$ \\
\hline \multicolumn{12}{|l|}{ Have pupils monitor their own } \\
\hline work (self-regulation) & 1.0 & 0.0 & 1.2 & 0.6 & 1.2 & 1.0 & 0.2 & 1.1 & 0.3 & 1.1 & $<1.0$ \\
\hline \multicolumn{12}{|l|}{ Have pupils evaluate their own } \\
\hline work (self-regulation) & 1.0 & 0.0 & 1.2 & 0.6 & 1.2 & 1.1 & 0.3 & 1.0 & 0.2 & 1.1 & $<1.0$ \\
\hline Use of the DI-structure & 2.4 & 1.1 & 3.7 & 0.8 & 3.6 & 2.4 & 1.0 & 2.5 & 0.7 & 2.6 & $25.4^{\star \star}$ \\
\hline
\end{tabular}

Note: Treatment group $n=27$; control group $n=24$. Sum scores and means for the ratings are based on a five-point scale: $1=$ no application of the skill, $5=$ clear application of the skill; $\star_{p}<0.05 ; \star \star p<0.01$; $\mathbf{M}=$ mean, $\mathbf{S D}=$ standard deviation; Adj. $M=$ adjusted means. 
their classes according to the instructional models described in the course and thus clearly model the desired instructional skills in their classes, they rarely followed this recommendation. In the first classes, a great deal of information was generally transmitted by the teacher educator. In the remaining classes, the presentation of theory alternated with concrete assignments in the form of mini-lessons or lesson plans.

On the average, the student teachers conducted relatively few lessons according to the direct instructional model at their co-operating schools. The supervising teachers were also not well informed by the teacher educators or the student teachers with regard to the goals and content of the experimental course on effective instruction. The instructional guide that explained the two instructional models for the supervising teachers was seldom used. Only a small number of the supervising teachers provided their student teachers with guided practice as they themselves practised the instructional skills.

\section{Data Collection}

Before the start of the course, each student teacher was observed during one lesson (between September and December 1994). After the course had been followed, each student teacher was again observed for one lesson (between January and February 1995). The course on effective instruction was conducted sometime between October and December 1994; training periods at the cooperating schools varied. In the same period, the evaluation questionnaires were distributed to all of the student teachers who participated in the course on effective instruction. The interviews with the teacher educators took place in March 1995.

The four scores for pupil engagement were averaged for each lesson to produce means for each class and each student teacher. For the observational data collected by the trained observers, the scale scores were computed by adding the values of the DIS items. For the observation data collected by the supervising teachers, the scale scores were averaged because the number of supervising teachers differed at the pre-test and post-test and because all of the supervising teachers did not complete all of the parts of the scale. In testing for possible differences between the treatment student teachers and the control student teachers, a level of significance of $5 \%$ was used (one-tailed). The unit of analysis was the student teacher (and her/his class). For a more detailed description of the design, instrumentation, and data collection, see Bakermans et al. (1995).

\section{Results}

When comparing the ratings of the trained observers and the supervising teachers for the treatment group prior to training and the control group, no initial significant differences were found for the scores on the Direct Instruction Scale (DIS). However, significant pre-test differences between the treatment 
TABLE II. Mean ratings by supervising teachers on variables from the Direct Instructional Scale (DIS), results of $t$-test on differences between preand post-test data for treatment and control student teachers, and ANCOVA test results

\begin{tabular}{|c|c|c|c|c|c|c|c|c|c|c|c|}
\hline \multirow[t]{3}{*}{ DIS/subscales/items } & \multicolumn{5}{|c|}{ Treatment group } & \multicolumn{5}{|c|}{ Control group } & \multirow[t]{3}{*}{$\mathbf{F}$} \\
\hline & \multicolumn{2}{|c|}{ Pre-test } & \multicolumn{3}{|c|}{ Post-test } & \multicolumn{2}{|c|}{ Pre-test } & \multicolumn{3}{|c|}{ Post-test } & \\
\hline & $\mathbf{M}$ & SD & $\mathbf{M}$ & SD & Adj.M & $\mathbf{M}$ & SD & $M$ & SD & Adj.M & \\
\hline DIS total (24 items, $\alpha=0.87$ ) & 2.7 & 0.7 & 3.1 & 0.6 & 3.1 & 2.8 & 0.7 & 3.2 & 0.5 & 3.3 & 1.5 \\
\hline \multicolumn{12}{|l|}{ Subscale presentation. } \\
\hline ( 9 items, $\alpha=0.71$ ) & 2.9 & 0.8 & 3.3 & 0.8 & 3.3 & 2.8 & 0.8 & 3.3 & 0.8 & 3.3 & $<1.0$ \\
\hline Daily review & 2.7 & 1.5 & 3.5 & 1.1 & 3.5 & 2.5 & 1.4 & $3.7^{\star}$ & 1.1 & 3.6 & $<1.0$ \\
\hline Activating prior knowledge & 2.7 & 1.3 & $3.6^{\star}$ & 1.1 & 3.5 & 2.9 & 1.6 & 3.5 & 1.1 & 3.6 & $<1.0$ \\
\hline State lesson goals & 2.8 & 1.2 & 2.7 & 1.4 & 2.6 & 2.8 & 1.5 & 2.7 & 1.1 & 2.7 & $<1.0$ \\
\hline Provide procedural facilitators & 3.1 & 1.2 & 3.7 & 1.1 & 3.6 & 3.3 & 1.1 & 3.0 & 1.3 & 3.0 & 1.6 \\
\hline Model the use of strategies & 3.4 & 1.2 & 3.5 & 1.1 & 3.5 & 3.1 & 1.1 & 3.4 & 1.2 & 3.4 & $<1.0$ \\
\hline \multicolumn{12}{|l|}{ Underline the importance of } \\
\hline Provide concrete examples & 3.5 & 1.5 & 3.5 & 1.5 & 3.6 & $\begin{array}{l}2.4 \\
3.7\end{array}$ & 1.4 & 3.9 & 1.2 & 3.9 & $<1.0$ \\
\hline Provide summaries & 2.4 & 1.2 & 2.7 & 1.3 & 2.6 & 2.0 & 1.4 & 2.7 & 1.3 & 2.8 & $<1.0$ \\
\hline Activate thinking processes & 3.3 & 1.3 & $3.5^{\star}$ & 1.1 & 3.5 & 2.9 & 0.9 & $3.5^{\star}$ & 1.2 & 3.5 & $<1.0$ \\
\hline \multicolumn{12}{|l|}{ Subscale guided practice } \\
\hline ( 5 items, $\alpha=0.58$ ) & 2.8 & 0.8 & $3.4^{\star}$ & 0.7 & 3.3 & 3.1 & 0.6 & $3.6^{\star}$ & 0.5 & 3.7 & $4.2^{\star}$ \\
\hline Provide clear assignments & 3.7 & 1.3 & 4.1 & 0.9 & 4.1 & 3.9 & 0.9 & 4.3 & 0.7 & 4.4 & 1.2 \\
\hline \multicolumn{12}{|l|}{ Have pupils make their strategies } \\
\hline explicit & 1.9 & 1.2 & $2.9^{\star}$ & 1.4 & 2.8 & 2.1 & 1.0 & $3.1^{\star}$ & 1.2 & 3.2 & $<1.0$ \\
\hline Checking for understanding & 2.8 & 1.1 & 3.1 & 1.3 & 3.1 & 2.7 & 1.1 & $3.4^{\star}$ & 0.9 & 3.4 & $<1.0$ \\
\hline Provide process feedback & 1.7 & 1.2 & $3.1^{\star \star}$ & 1.3 & 3.1 & 2.4 & 1.1 & 2.8 & 1.0 & 2.9 & $<1.0$ \\
\hline Provide correctives & 3.3 & 0.9 & $3.9 *$ & 1.1 & 3.8 & 4.3 & 0.7 & 4.3 & 0.8 & 4.5 & 3.1 \\
\hline \multicolumn{12}{|l|}{ Subscale independent practice } \\
\hline (10 items, $\alpha=0.85$ ) & 2.4 & 0.8 & 2.8 & 0.7 & 2.8 & 2.7 & 0.8 & 3.0 & 0.6 & 3.0 & 1.2 \\
\hline Engage in reciprocal teaching & 1.6 & 1.0 & 1.6 & 1.1 & 1.5 & 1.4 & 1,1 & 2.0 & 1.1 & 2.1 & 1.5 \\
\hline Stimulate pupil engagement & 3.1 & 1.0 & $3.7^{\star}$ & 0.9 & 3.6 & 3.3 & 1.0 & 3.8 & 0.9 & 3.9 & $<1.0$ \\
\hline \multicolumn{12}{|l|}{ Effective monitoring (pupils begin } \\
\hline work quickly) & 3.0 & 1.2 & $3.9^{\star}$ & 1.2 & 4.0 & 4.1 & 1.0 & 4.3 & 0.7 & 4.1 & $<1.0$ \\
\hline Have pupils help each other & 2.8 & 1.5 & 2.9 & 1.3 & 2.9 & 3.4 & 1.3 & 3.3 & 1.2 & 3.3 & 1.0 \\
\hline Provide cues for transfer & 2.2 & 1.3 & 2.0 & 1.2 & 2.0 & 2.0 & 1.3 & 2.8 & 1.4 & 2.8 & $\mathbf{3 . 0}$ \\
\hline Active processing of information & 2.0 & 1.4 & 2.3 & 1.2 & 2.4 & 2.3 & 1.3 & 2.5 & 1.0 & 2.5 & $<1.0$ \\
\hline \multicolumn{12}{|l|}{ Have pupils plan their work } \\
\hline (self-regulation) & 2.3 & 1.3 & 2.8 & 1.4 & 2.7 & 2.5 & 1.1 & $3.2^{\star \star}$ & 1.1 & 3.2 & 1.2 \\
\hline \multicolumn{12}{|l|}{ Have pupils monitor their own } \\
\hline work (self-regulation) & 1.7 & 1.1 & $2.5^{\star}$ & 1.2 & 2.5 & 2.4 & 1.1 & 2.8 & 1.1 & 2.7 & $<1.0$ \\
\hline \multicolumn{12}{|l|}{ Have pupils evaluate their own } \\
\hline work (self-regulation) & 1.8 & 1.2 & $2.7^{\star}$ & 1.3 & 2.7 & 2.1 & 1.1 & $3.1^{\star \star}$ & 1.1 & 3.1 & $<1.0$ \\
\hline Use of the DI-structure & 2.5 & 0.8 & 2.7 & 1.0 & 2.6 & 2.6 & 1.1 & 2.8 & 1.1 & 2.9 & $<1.0$ \\
\hline
\end{tabular}

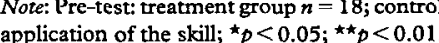


group and the control group were apparent for pupil engagement. The pupils in the classes of the treatment student teachers were found to be more on-task at pre-test $(84 \%)$ than the pupils in the classes of the control student teachers $(77 \%)$. This difference in time-on-task should therefore be kept in mind when interpreting the results of this study.

A one-tailed $t$-test for paired samples was used to examine the difference between the pre- and post-test data for the treatment group. The question was whether the treatment student teachers made better use of the desired behaviours at post-test than at pre-test. Due to initial differences in pupil engagement, an analysis of covariance (ANCOVA) was used to examine the differences between the treatment and control groups (with the initial engagement and DIS scores as covariates). A summary of the DIS scores from the trained observers and the results of the tests are presented in Table I.

The data displayed in Table I show the course on effective instruction to affect the instructional behaviours of the student teachers positively. Significant differences between the pre- and post-test scores for the treatment student teachers were found for the total mean score from the DIS and the three subscales from the DIS: presentation, guided practice, and independent practice $(p<0.01)$. The treatment student teachers were found to use the instructional behaviours more effectively at post-test than at pre-test. No significant differences between the pre- and post-test scores for the control student teachers were found for the total mean score from the DIS or the three subscales.

The post-test performance of the treatment student teachers appeared to be significantly better than their pre-test performance on 13 of the 24 ratings (54\%) $(p<0.05)$. For the control student teachers, four of the 24 ratings were found to be significantly positive at post-test and two significantly negative (namely, provide summaries and have pupils help each other).

When the adjusted mean scores for the treatment student teachers are compared to those for the control student teachers (see Table I), significant differences were found for the total mean score $(F(1,50)=17.6, p<0.01)$ and the three subscales from the DIS: presentation $(\mathrm{F}(1,50)=13.5, p<0.01)$, guided practice $(\mathrm{F}(1,50)=4.5, p=<0.05)$, and independent practice $(\mathrm{F}(1,50)=11.6, p<0.01)$. Compared to the control student teachers, the treatment student teachers were rated more effectively on four of the nine presentation skills (daily review, underline the importance of strategies, provide summaries, and activate thinking processes); on two of the five guided practice skills (provide clear assignments and provide correctives); and on three of the 10 independent practice skills (active processing of information, have pupils plan their own work [self-regulation], and use of the DI-structure)

The SPSSX program MANOVA was used to conduct a number of univariate analyses of variance on the adjusted mean scores for the two groups (treatment, control) with the following variables controlled for separately: teacher training college (location A, B, C), student teacher's gender, subject matter (languages: Dutch, English, German; science: mathematics, physics, technology; social studies: geography, history, economics), and school 
TABLE III. Average percentages of pupils on-task, results of $t$-test on differences between pre- and post-test data for treatment and control student teachers, and ANCOVA test results

\begin{tabular}{|c|c|c|c|c|c|c|c|c|c|c|c|}
\hline \multirow{3}{*}{ Student teachers' classes } & \multicolumn{5}{|c|}{ Treatment group } & \multicolumn{5}{|c|}{ Control group } & \multirow[t]{3}{*}{$\mathrm{F}$} \\
\hline & \multicolumn{2}{|c|}{ Pre-test } & \multicolumn{3}{|c|}{ Post-test } & \multicolumn{2}{|c|}{ Pre-test } & \multicolumn{3}{|c|}{ Post-test } & \\
\hline & $\mathbf{M}$ & SD & $\mathbf{M}$ & SD & Adj.M & M & SD & $M$ & SD & Adj.M & \\
\hline $\begin{array}{l}\text { Percentage of pupils on-task } \\
\text { (whole lesson) }\end{array}$ & 84.2 & 10.1 & 86.7 & 9.2 & 86.8 & 76.9 & 14.2 & $84.4^{\star}$ & 8.6 & 84.3 & $<1.0$ \\
\hline Moment 1 (after 10 minutes) & 86.6 & 20.2 & 87.6 & 14.6 & 87.9 & 81.9 & 20.1 & 89.5 & 9.8 & 89.2 & $<1.0$ \\
\hline Moment 2 (after 20 minutes) & 86.0 & 11.5 & 88.2 & 12.0 & 88.1 & 77.7 & 22.4 & $86.5^{\star}$ & 10.2 & 86.6 & $<1.0$ \\
\hline Moment 3 (after 30 minutes) & 86.8 & 9.1 & 86.9 & 11.6 & 85.8 & 75.5 & 13.8 & $83.9^{\star}$ & 11.4 & 85.0 & $<1.0$ \\
\hline Moment 4 (after 40 minutes) & 77.5 & 15.5 & $84.2^{\star}$ & 11.8 & 83.8 & 72.1 & 17.2 & 77.7 & 22.6 & 78.1 & 1.3 \\
\hline
\end{tabular}

Note: ${ }^{\star} p<0.05$ 
type: (low: junior secondary vocational and junior general secondary education; intermediate: senior general secondary education; high: pre-university education). A significant interaction was found between treatment and subject matter for the subscale independent practice $(\mathrm{F}(2,50)=3.5, p=<0.05)$ and between treatment and school type for the subscale presentation $(F(2,49)=4.3$, $p<0.05$ ). The scores for the treatment student teachers in the language departments increased significantly for the subscale independent practice while the scores for the control student teachers in the language departments decreased significantly. The scores for the treatment student teachers who taught in the 'highest' type of school (pre-university education) increased significantly for the subscale presentation while the scores for the control student teachers who taught in the same type of school decreased significantly.

In Table II, the DIS results from the supervising teachers for the treatment and control student teachers are presented. Significant differences between the pre- and post-test scores for the treatment student teachers were only found for the subscale guided practice $(p<0.05)$. Significant differences between the preand post-test scores for the control student teachers were also found for the subscale guided practice $(p<0.05)$. No significant differences were found between pre-test and post-test for the treatment and control student teachers for the mean score on the DIS and for the subscales presentation and independent practice.

With regard to the specific ratings of the performance of the treatment student teachers by the supervising teachers, nine of the 24 post-measures $(38 \%)$ were found to be significantly better than the pre-measures. For the control student teachers, six of the 24 post-measures $(25 \%)$ were found to be significantly different from the pre-measures.

When the ratings of the treatment student teachers by the supervising teachers are compared to those of the control student teachers using adjusted mean scores, no significant implementation effects were found for the total mean score from the DIS or the subscales presentation and independent practice (see Table II). Significant implementation effects were found for the subscale guided practice. Both trained and untrained student teachers improved their guided practice skills. Contrary to expectation, the untrained student teachers scored higher on this subscale than the trained student teachers. The ratings from the supervising teachers showed no significant interaction effects between treatment and control variables (teacher training college, student teacher's gender, subject matter, or school type).

The results in Table III show the course on effective instruction to have no significant effect on the pupil engagement rates. After completion of the course, the treatment group pupils exhibited no significant increases in their on-task scores: $84 \%$ of the pupils were classified as on-task prior to training and $87 \%$ were classified as on-task scores after training. A significant increase in on-task scores was only found at observational point 4 (after 40 lesson minutes). A significant effect on pupil engagement rates was nevertheless found for the control group pupils: $77 \%$ of the pupils were classified as on-task prior to 
training and $84 \%$ were classified as on-task after training. This increase was particularly evident at observational points 2 and 3 (after 20 and 30 lesson minutes). The difference in the adjusted mean scores for the treatment and control group pupils was not significant (pre-measures of engagement rates were used as the adjustment). Note that the interpretation of the results with regard to the pupil engagement rates is complicated by the fact that the treatment group pupils scored significantly higher at pre-test than the control group pupils. No significant interaction effects were found between treatment and control variables (teacher training college, student teacher's gender, subject matter, or school type).

The results from the questionnaires and the interviews (tables not included here; see Bakermans et al., 1995) suggest that the course was clearly used by the student teachers. The student teachers who returned the questionnaire reported the content of the course to be very helpful because it provided many concrete, specific, and practical suggestions. The examples in the text were rated as particularly valuable because they provided concrete illustrations of how to implement the particular instructional skills in a variety of subject areas. The instructional model of executive acting was rated by the student teachers as more useful than the model of strategic acting. Most of the student teachers also indicated an intention to apply the acquired instructional skills in their future lessons. The course was rated by the teacher educators as valuable, and they expressed a desire to use the programme (or parts of it) in their curriculum for the next year.

\section{Discussion}

The results of the present study suggest that the training programme for effective instruction can have a positive effect on the instructional skills of student teachers. The treatment student teachers were generally rated higher by the trained observers on the Direct Instruction Scale (DIS) than the control student teachers. Significant differences between the trained and untrained student teachers were found for the DIS as a whole and for the three subscales, presentation, guided practice, and independent practice.

Contrary to the ratings from the trained observers, the ratings from the supervising teachers revealed no differences between the instructional skills of the trained and untrained student teachers for the DIS as a whole and for the subscales presentation and independent practice. A significant effect was found for the subscale guided practice. Contrary to expectation, the untrained student teachers improved their guided practice skills to a greater extent than the trained student teachers.

The difference in the observations by the trained observers and the supervising teachers might be explained as follows. Although the supervising teachers received a short description of the instructional skills covered in the training programme, only a few of the supervising teachers were actually able to study these skills and consider them in their feedback to the student teachers. The 
majority of the supervising teachers used the one-sentence description of the instructional skills from the DIS to rate their student teachers and interpreted this short description in their own way. The trained observers, in contrast, knew the content of the training programme and were specially instructed in the operational definition of the instructional skills described in the DIS. Moreover, the observations of the trained observers showed the supervising teachers not always to be present when the student teachers taught their pre- and post-test lessons. Rather, the supervising teachers often completed the DIS using global impressions of the qualities of their student teachers. In the present study, more weight was therefore attached to the ratings of the trained observers than to the ratings of the supervising teachers. The student teachers also received little or no feedback with regard to the instructional skills relevant to the two instructional models. A closer relation between the supervising teachers and the student teachers and a closer relation between the teacher educators and the supervising teachers with regard to the content of the training programme might have produced significant differences in the supervising teachers' perceptions of the trained versus untrained student teachers.

With regard to the pupil engagement rates, no significant differences were found between the trained and untrained student teachers. It should be noted, however, that the pupils in the classes of the treatment student teachers scored significantly higher than the pupils in the classes of the control student teachers at pre-test ( $84 \%$ versus $77 \%)$. After completion of the course, the on-task scores of the pupils in the classes of the treatment student teachers increased; given their initially lower on-task score, however, the scores of the control student teachers increased even more than those of the treatment student teachers. The treatment student teachers, nevertheless, appeared to be more successful at keeping the time-on-task levels at a high level throughout the lesson than the control student teachers. Keeping pupils highly involved, even after 40 minutes, appears to be an effect of training. Given the initial differences in the engagement rates at pre-test, however, the possibility of a training effect on time-on-task levels should be further evaluated in future research as statistical adjustment for pre-test differences used in the present study cannot be assumed to control completely for their influences on post-test scores (see Reichardt, 1979).

In light of the higher time-on-task levels at pre-test for the pupils in the classes of the treatment student teachers than for the pupils in the classes of the control student teachers, it can be hypothesised that the pupils in the classes of the treatment student teachers were more willing to learn than the pupils in the classes of the control student teachers. This may have made it easier for the treatment student teachers to implement the desired instructional skills and suggests that the teacher training effect may have been confounded by a pupil willingness to listen attentively to the student teacher and perform the assigned tasks.

In retrospect, the training of the experienced teacher educators appears to have been too short. Discussions with the student teachers showed no employ- 
ment of modelling techniques by the educators to make the instructional skills explicit. The training of the teacher educators in the present study did not enable the teacher educators to practise what they preached. This means that the importance of cognitive modelling techniques should receive greater emphasis in future implementation of the programme. The teacher educators in the present study were also not in a position to spend much time on the conduct of the training programme. The conversations with the teacher educators and the student teachers revealed that the conduct of the training programme, and especially the assignments for the student teachers, required more time. The three educators could not set aside time to coach their student teachers at the co-operating school, moreover. If more time can be devoted to the clinical supervision of the student teachers in the future, greater attention can be paid to the instructional model of strategic acting. The student teachers in the present study appeared to prefer the instructional model of executive acting because of its prevalence in teacher training and secondary teaching.

The results in this study showed the scores on the subscale presentation to increase for the trained student teachers teaching in pre-university education schools and decrease for the untrained student teachers in these schools. In other school types, both the trained and untrained student teachers progressed with the trained student teachers nevertheless progressing more than the untrained student teachers. An explanation for this interaction effect is difficult to provide. It might be that the pupils in the pre-university education schools are more focused on the acquisition and integration of new information than pupils in other types of schools and that the trained student teachers dealt with this heightened interest in a more effective manner than the untrained student teachers. Moreover, the results of this study showed the scores on the subscale independent practice to increase for the trained student teachers in the language departments and decrease for the untrained student teachers in these same departments. The trained language student teachers appeared to use the desired instructional behaviours during the independent practice phase of the lesson more effectively than the untrained language student teachers, which may be attributed to the training.

The participants in the present study were student teachers from three different teacher education colleges enrolled in their second or third year. Colleges $\mathrm{A}$ and $\mathrm{C}$ included student teachers in their second year of training while college $B$ included student teachers in their third year of training. One might expect the student teachers in their third year of training to perform better than the student teachers in their second year of training although no differences in the DIS scores and pupil engagement rates for these groups were found. Despite their enrolment in the third year, the student teachers in college B had the same amount of field experience as the student teachers in colleges $\mathrm{A}$ and $\mathrm{C}$, namely, 2 years. The findings of the present study suggest that a course on effective instruction similar to that described here can be a successful training activity for secondary student teachers in any case. 


\section{Acknowledgements}

The research reported here was supported by the Protestant Educational Advisory Centre (CPS), Hoevelaken. The authors gratefully acknowledge the following persons for their contribution to this study: G. de Boer (CPS), Y. Leenders (CPS), A. v.d. Horst (CPS), L. Bouts (RTD KUN), and the participating teacher educators, supervising teachers, and student teachers.

\section{REFERENCES}

Bakermans, J., Franzen, Y. \& Van Hoof, M. (1995) Effectieve instructie in het voortgezet onderwij: een evaluatie-onderzoek naar het trainingsprogramma [Effective instruction in secondary schools: evaluation of a training programme], unpublished Masters thesis, Department of Educational Sciences, University of Nijmegen.

Bereiter, C. \& Scardamalia, M. (1987) The Psychology of Written Composition (Hillsdale, NJ, Lawrence Erlbaum Associates).

BoRkowsKI, J.G. \& MUTHUKRISHNA, N. (1992) Moving metacognition into the classroom: 'working models' and effective strategy teaching, in: M. PRESSLEY, K.R. HARRIs \& J.T. GuTHRIE (Eds) Promoting Academic Competence and Literacy in School, pp. 477-501 (San Diego, CA, Academic Press).

BROPHY, J. \& GoOD, T. (1986) Teacher behaviour and student achievement, in: M.C. WrTTROCK (Ed.) Handbook of Research on Teaching, pp. 328-375 (New York, Macmillan).

Collins, A., BRown, J.S. \& NewMaN, S.E. (1989) Cognitive apprenticeship: teaching the crafts of reading, writing, and mathematics, in: L.B. RESNICK (Ed.) Knowing, Learning, and Instruction. Essays in honor of Robert Glaser, pp. 453-494 (Hillsdale, NJ, Lawrence Erlbaum Associates).

PAIINCSAR, A.S. \& BROWN, A.L. (1984) Reciprocal teaching of comprehension-fostering and comprehension-monitoring activities, Cognition and Instruction, 1, pp. 117-175.

PALINCSAR, A.S. \& BROWN, A.L. (1989) Instruction for self-regulated reading, in: L.B. RESNICK \& L.E. KIOPFER (Eds) Toward the Thinking Curriculum: current cognitive research, pp. 19-39 (Alexandria, Association for Supervision and Curriculum Development).

Pressley, M., GoodChIID, F., FleET, J. \& ZajChowski, R. (1989) The challenges of classroom strategy instruction, Elementary School Foumal, 90, pp. 301-342.

Pressley, M. et al. (1990) Cognitive Strategy Instruction (Cambridge, Brookline Books).

REICHARDT, C.S. (1979) The statistical analysis of data from non-equivalent group designs, in: T.C. COOK \& D.T. CAMPBELL (Eds) Quasi-experimentation: design and analysis issues for field settings, pp. 147-205 (Chicago, IL, Rand McNally).

Rosenshine, B. \& MEISTER, C. (1992) The use of scaffolds for teaching higher-level cognitive strategies, Educational Leadership, 49, pp. 26-33.

Rosenshine, B. \& STEvens, R. (1986) Teaching functions, in: M.C. WrTTrock (Ed.) Handbook of Research on Teaching, pp. 376-391 (New York, Macmillan).

SchoEnfeld, A.H. (1985) Mathematical Problem-solving (Orlando, FL, Academic Press).

SHUELL, T. J. (1988) The role of the student in learning from instruction, Contemporary Educational Psychology, 13, pp. 276-295.

STUURGRoep Profiel TwEede FASE VoORTGEZet ONDERwIJs (1994) De tweede fase vernieuwt. deel 2 [The restructuring of the second phase of secondary education, part 2] (The Hague, Porsius).

VAN PARREREN, C.F. (1988) Ontwikkelend onderwijs [Developmental Education] (Leuven, Acco). Veenman, S., LeENDERS, Y., MEYer, P. \& SANDERS, M. (1993) Effects of a pre-service teacher preparation programme on effective instruction, Educational Studies, 19, pp. 3-18. 
VeEnman, S. (Ed.), Bakermans, J., Franzen, Y. \& VAN Hoof, M. (1994) Effectieve instructie in het voortgezet onderwijs [Effective instruction in secondary schools: learning to teach with the directinstructional model] (Hoevelaken, Christelijk Pedagogisch Studiecentrum).

WINER, B.J. (1971) Statistical Principles in Experimental Design (New York, McGraw-Hill). 